\title{
Implementation of Egypt Sat-1 Satellite Test Center Using LabVIEW
}

\author{
Mohamed Elhady Keshk, Mohamed Ibrahim, Noran Tobar, Hend Nabil, Mohamed Elemam
}

Testing and Devleopment of Satellites Systems Group, Egyptian Space Program, NARSS, Cairo, Egypt

\section{Email address:}

m.elhady@narss.sci.eg (M. E. Keshk), m.ibrahim@narss.sci.eg (M. Ibrahim), N.Tobar@narss.sci.eg (N. Tobar), H.Nabil@narss.sci.eg (H. Nabil), M.Emam@narss.sci.eg (M. Elemam)

\section{To cite this article:}

Mohamed Elhady Keshk, Mohamed Ibrahim, Noran Tobar, Hend Nabil, Mohamed Elemam. Implementation of Egypt Sat-1 Satellite Test Center Using LabVIEW. American Journal of Software Engineering and Applications. Vol. 4, No. 5, 2015, pp. 80-85.

doi: $10.11648 /$ j.ajsea.20150405.11

\begin{abstract}
In each stage of any satellite design cycle, it is required to have test system that verifies the operational functions of each satellite subsystem and the integration operation among the satellite subsystems. Usually, these test systems consist of many hardware's and these hardware's are very complicated and occupied large space. The first Egyptian satellite, Egypt Sat-1, has a test center; a place where the satellite integration test sequences are carried out. This center consists of complicated hardware. In this paper a new trend, using LabView tool with National Instrument (NI) chassis, is used to build a satellite test center (STC) prototype that reduce the cost, complexity and occupied area of the STC. So the new trend tests the ability to replace the Egypt Sat-1 test center. The results of this paper shows that the quality of the new trend compared to the existed Egypt Sat-1 test center.
\end{abstract}

Keywords: Satellite Test Center, Space, Engineering Model

\section{Introduction}

The entrance of the space field is surrounding by the risks. One of them is the failure of the satellite subsystem operation after launching. So every satellite design process must be tested and verified before the launching of the satellite. To achieve that it is required to have a test center that has the capabilities to perform pre-launching tests. In addition to prelaunching tests that applied to each subsystem during the design procedures of the satellite, it is also required to test new operation plans on the ground before applying it on the satellite during its life time. So test center has two important functions one is pre-launching tests and post-launching tests.

The Satellite Test Center (STC) of Egypt Sat-1 satellite consists of control machine that initiates and performs all test programs, checkout equipment $(\mathrm{CoE})$ for each subsystem on the satellite and a satellite mockup. Each $\mathrm{CoE}$ performs some functions to implement and analyze the test program contain complex hardware that need in order complex data exchange and interface among $\mathrm{CoE}$ and the control machine.

Many studies are implemented in different fields using Labview; labview can be used in simulation of satellite camera (payload) subsystem [4], also NASA used labview in automated testing of Micro shutters [5], labview can also used in Building a Satellite Navigation Test Platform Using the NI Vector Signal Transceiver [6], in channel modeling of mobile systems [7], used for testing satellite GPS receiver [8], [9] and in FPGA application[10].

The remainder of the paper is organized as follows. Section II has an overview on the proposed STC. Section III defines the Integration Test Machine (ITM). Section IV defines the basic functions of Telemetry Control (TC) CoE. Section V defines the basic functions of Payload CoE. Section VI defines the basic functions of and mathematical model of the Power CoE Section VII defines the basic functions of Satellite simulator. Section VIII conclusion of the proposed STC work.

\section{STC}

A new implementation of STC using LabView tool with less hardware is proposed in this paper which performs the same functions of the Egypt sat-1 STC but with less complexity, development time, and cost within small area.

For simplicity, the control machine (ITM) will be implemented to perform the same functions as the configuration control console (CCC) that in Egypt Sat-1 STC. To verify the proposed STC; Payload, Power, Telemetry 
control (TC) CoE's will be simulated using LabView tool in addition to a satellite simulator. Each subsystem will be implemented using LabView program running on NI machine.

A. STC Structure

The concept of the proposed STC is to make integration test among satellite simulator and Check Test Equipment CoE's under the control of ITM as in figure 1, i.e. the ability to replace the existing engineering model by the proposed STC system.

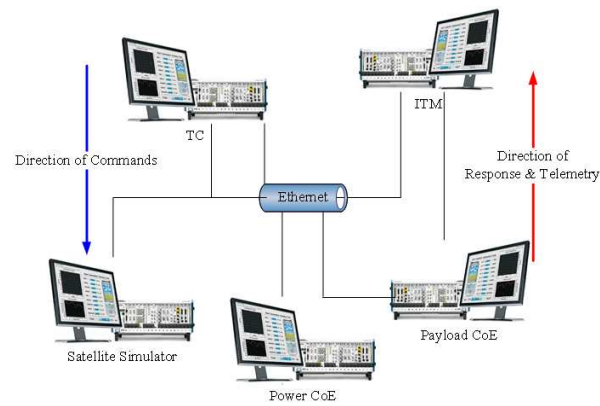

B. Data Exchange Interfaces

- TCP/IP, to transfer the commands between TC and satellite simulator.

- FTP, to transfer Telemetry file from satellite simulator to ITM.

- Reflected Memory Card, to adjust the synchronization among the whole system parts and to transfer the image from satellite simulator to Payload CoE.

\section{ITM}

ITM is the main part of the Satellite Test Center (STC), which is used for managing and monitoring of complex integration test (CIT) before, during and after the test program. Figure 2 illustrates the flow chart of ITM sequence operation.

Fig. 1. STC System Structure.

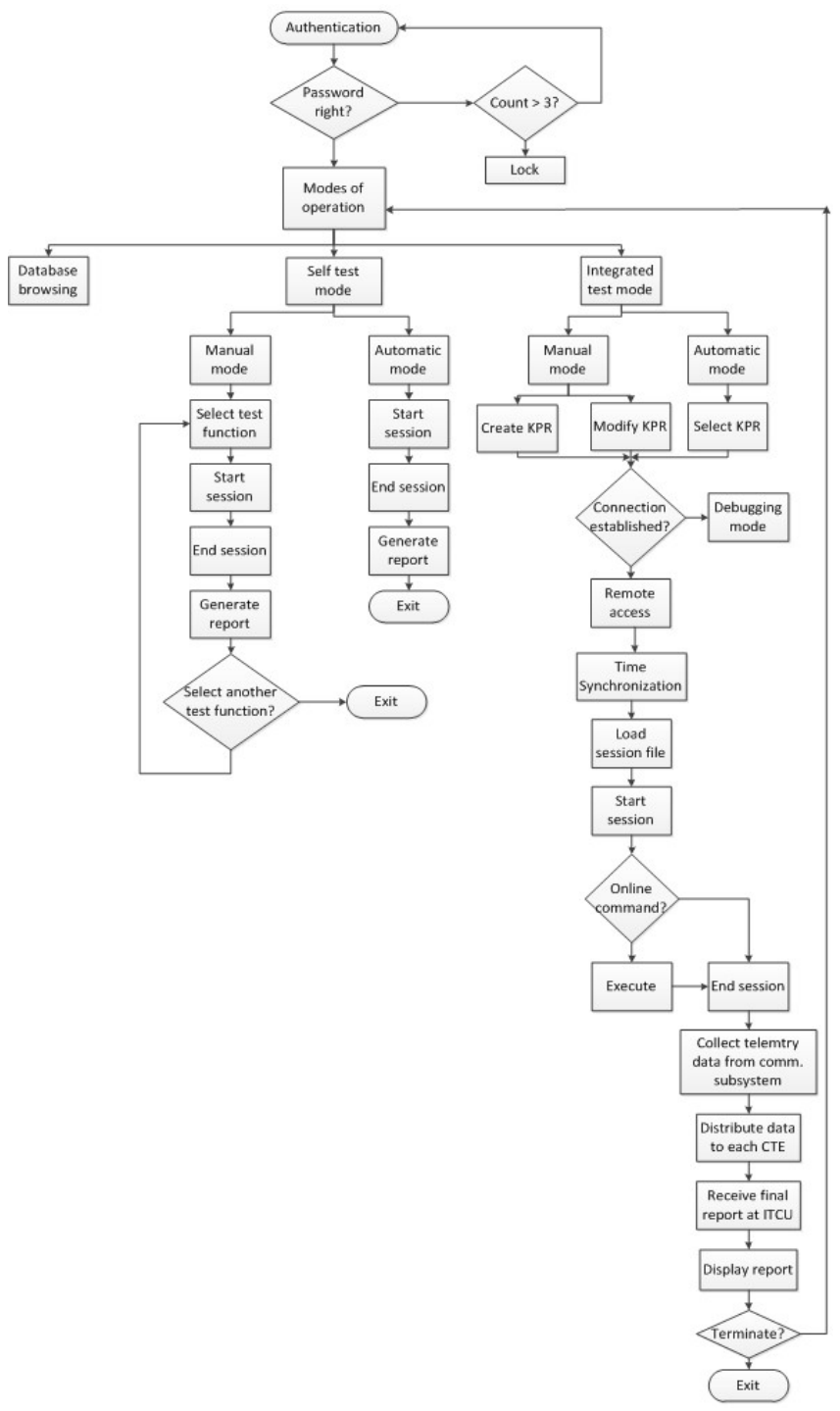

Fig. 2. ITM flow chart. 
Before the test program, the ITM functional requirements are network administration, access authentication, checking of connection presence with subsystem CoE's, selecting the operational mode type, selecting the test type (integrated or Self-test), selection of the test program, Loading the initial data for the test program session and exchanging the data between the ITM and the CoE's.
During the test program session; TC CoE monitors the CoE's and Satellite subsystems status. After test program session; ITM receives the telemetry data from the simulator then send them to their CoE's by using file transfer protocol (FTP), Receives, displays \& archives the test results from satellite CoE's. Figure 3 illustrate GUI of the ITM.

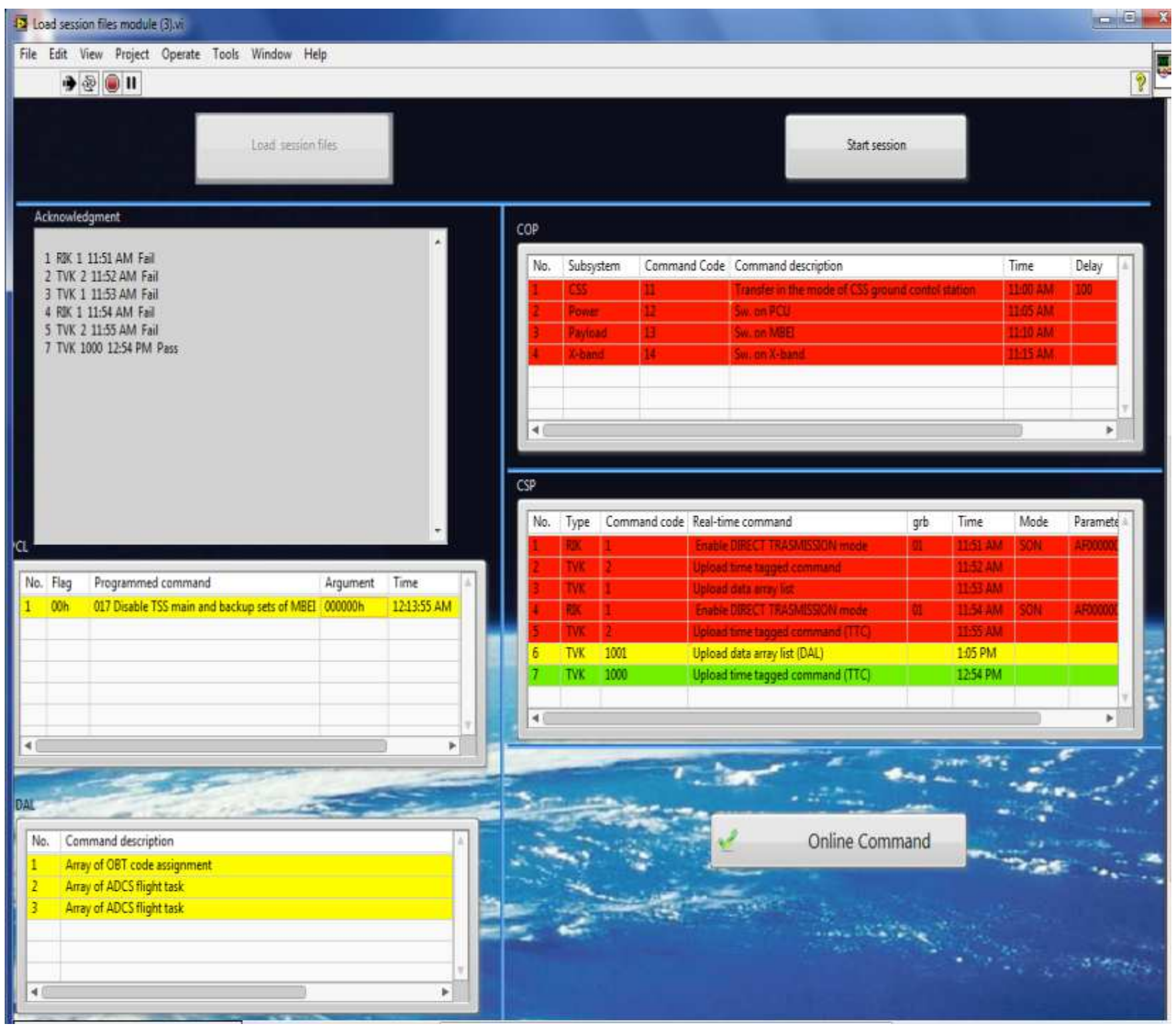

Fig. 3. ITM GUI.

\section{TC CoE}

After the reception of the test program session from ITM, TC CoE plays an important role in the execution of the test program session and monitoring each test program command. After the test program session, TC $\mathrm{CoE}$ sends the collected telemetry to ITM. First, TC Start the session then monitoring the execution of the session, receiving the acknowledgments of the session program and also it has the ability to sending on-line commands during session, Measuring of $\mathrm{CE}$ operating time and measuring of S-BAND OBE operating time.

\section{Payload CoE}

The main function of the Payload CoE is to receive a prestored image in the satellite simulator to analyze, verify and compare this with the one stored in it. The verification of the received image is depending on the comparison result of the two images, and the comparator factor is the resolution. 
Figure 4 illustrate GUI of the Payload CoE.

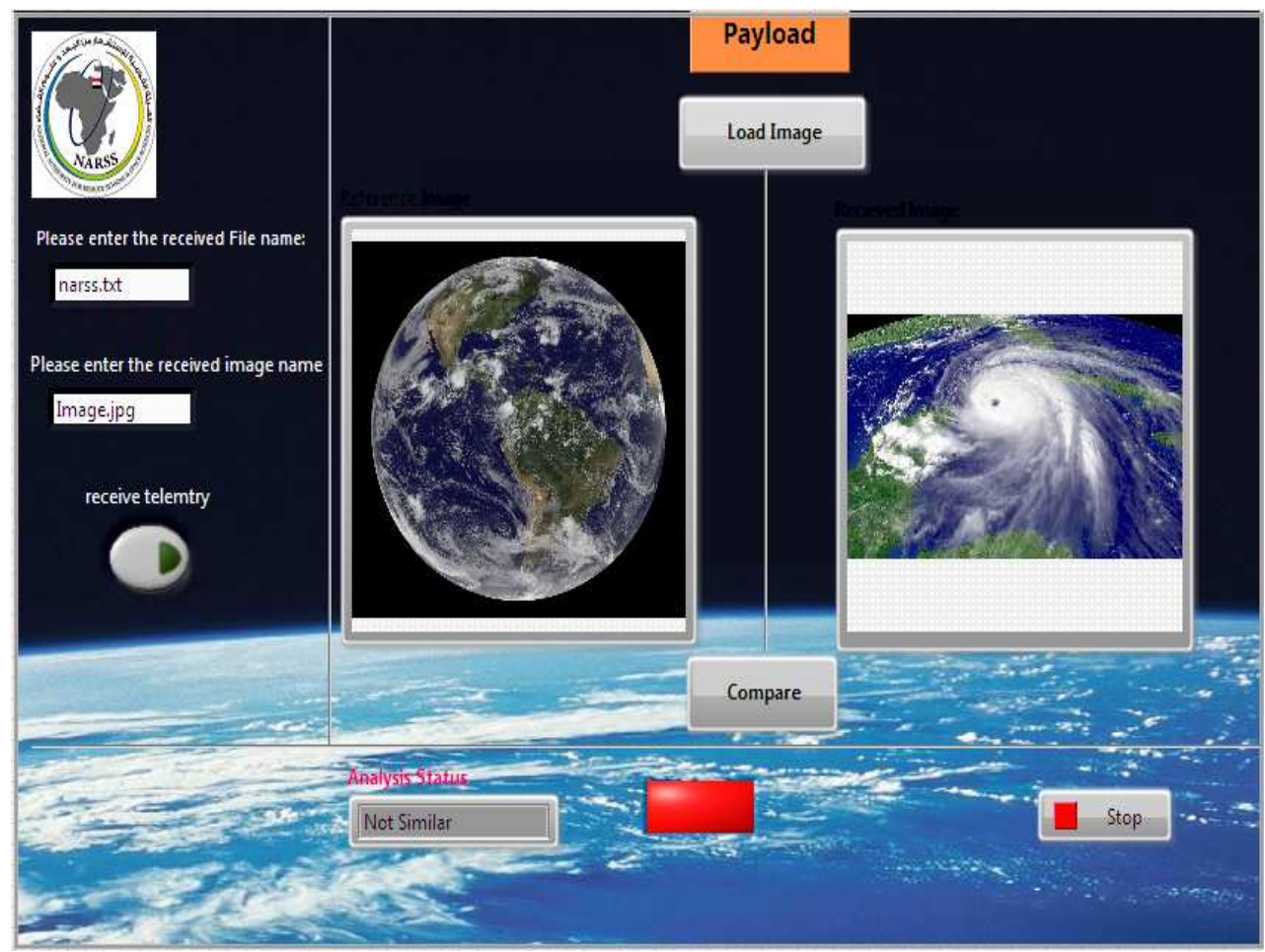

Fig. 4. Payload GUI.

\section{Power CoE}

The purposes of the power CoE are; Switch on the satellite simulator, provide the whole system by the required power needed and receiving the telemetry of the power subsystem from satellite simulator and analyzing them. Figure 5 shows the solar array simulator analysis report under the variation of temperature between 5Co and $40 \mathrm{Co}$ seen that as temperature increase the voltage decrease and current increase until the temperature reaches $40 \mathrm{Co}$, the temperature decreases again till $5 \mathrm{Co}$, to simulate temperature variation in orbit.

\begin{tabular}{|c|c|c|c|c|c|}
\hline \multicolumn{6}{|c|}{ Solar Array Report } \\
\hline & & $\begin{array}{l}\mathrm{tim}= \\
0.000000\end{array}$ & $\begin{array}{l}\text { temp } \\
10.000000\end{array}$ & $\begin{array}{l}\text { volt } \\
31.71510 \varepsilon\end{array}$ & $\begin{array}{l}\text { current } \\
2.469651\end{array}$ \\
\hline & & 1.000000 & 15.000000 & 29.833661 & 2.493152 \\
\hline & & 2.000000 & 20.000000 & 28.402727 & $2517 \mathrm{C} 01$ \\
\hline & & 3.000000 & 25.000000 & 27.203360 & 2540887 \\
\hline & & 4.000000 & 30.000000 & 26.150622 & 2.564671 \\
\hline & & 5.000000 & 35.000000 & 25.197011 & 2588282 \\
\hline Max.Voltage & 34.6897 & 6.000000 & 40.000000 & 24.314449 & 2.611679 \\
\hline Min.Voltage & 24.3144 & 7.000000 & 35.000000 & 25.197011 & 2588282 \\
\hline Max.Current & 26117 & 8.000000 & 30.000000 & 26.150622 & 2.564671 \\
\hline IVlax.current & 2.0117 & 9.000000 & 25.000000 & 27.203360 & 2.540887 \\
\hline Min.Current & 2.4475 & 10.000000 & 20.000000 & 28.402727 & $2517 \mathrm{Co1}$ \\
\hline Max.Temperature & 40.00 & 11.000000 & 15.000000 & 29.833661 & 2.493152 \\
\hline Min.Temperature & 5.00 & 12.000000 & 10.000000 & 31.715108 & 2.469651 \\
\hline & & 13.000000 & 5.000000 & $\Xi 4.689683$ & 2.447507 \\
\hline
\end{tabular}

Fig. 5. Power subsystem analysis report.

\section{Satellite Simulator}

Satellite simulator contains the following subsystems;
Payload and Power for simplicity.

The simulation of the power subsystem is divided into two parts; Solar Array and Battery.

A. Solar Array Simulation 
The selected functions of solar array simulator can be described as following; Get maximum power point voltage, current \& operating temperature, send this values instantaneously to Power CTE, graph represents VI-Curve at each temperature, create telemetry file (TDMS) and send it to power CTE using FTP.

The following equations are used To model the solar array mathematically using Egypt Sat-1 satellite solar array as reference [1]:

$$
\begin{gathered}
I=I p h-I s\left(e^{\frac{q(v+i R s)}{A K N S T c}}-1\right)-\frac{(V+I R s)}{R s h} \\
I s=\operatorname{Irs}\left(\frac{T c}{T r}\right)^{3} *\left(e^{\left(\frac{q E g}{A K}\left(\frac{1}{T r}-\frac{1}{T c}\right)\right)}\right) \\
I r s=\frac{I s h-\frac{V o c}{R s h}}{\left(e^{\frac{q V O C}{A K N S T r}-1}\right)} \\
V O c=\ln \left(\frac{I s c}{I o}+1\right)\left(\frac{A K T c}{q}\right)
\end{gathered}
$$

The symbols are defined as in Table 1 .

B. Battery Simulation

The selected functions of solar array simulator can be described as following; It Simulate Charging and discharging of the battery, representing battery current, Volt \& temperature, send this values instantaneously to Power CTE, it shows where battery charging or discharging and if it is ready to used or not, create telemetry file(TDMS) and send it to power CTE using FTP.

A NiCd battery is simulated with the following characteristics; Range of CB operational voltages: 24-34, Number of CB used: 1, Range of temperature: -5 to $+50^{\circ} \mathrm{C}[3]$.

In Figure 6, a portion of GUI that represent power subsystem.

The second simulated subsystem is Payload which send taken image to payload $\mathrm{CoE}$ using FTP, receive command (CSP/Online) using TCP and execute this command, create telemetry file and send it to Payload CTE using FTP. Figure 7 shows Payload subsystem simulator.

Table 1. Symbols Definition [1].

\begin{tabular}{lll}
\hline \multirow{2}{*}{ Parameters } & Attributes & Value \\
\cline { 2 - 3 } Iph & Table column subhead & 2.561176 \\
Irs & Photo current of the SPV module & $1.73071 * 10^{\wedge}-13$ \\
Rs & Diode reverse saturation current & 0.294 \\
Rsh & Series resistance in the equivalent circuit of the module & 639.302495 \\
A & Shunt resistance in the equivalent circuit of the module & 1.3 \\
Voc & Diode quality factor & 43.532 \\
Ish & Open circuit voltage of the module & 2.56 \\
Vmp & Short circuit current of the module & 38.032 \\
Imp & Maximum power point voltage & 2.412 \\
Ki & Maximum power point voltage and current & $1.381 \times 10-23$ \\
Eg & Boltzman's constant & 1.1 \\
qe & Band gap energy & Amp \\
\hline
\end{tabular}

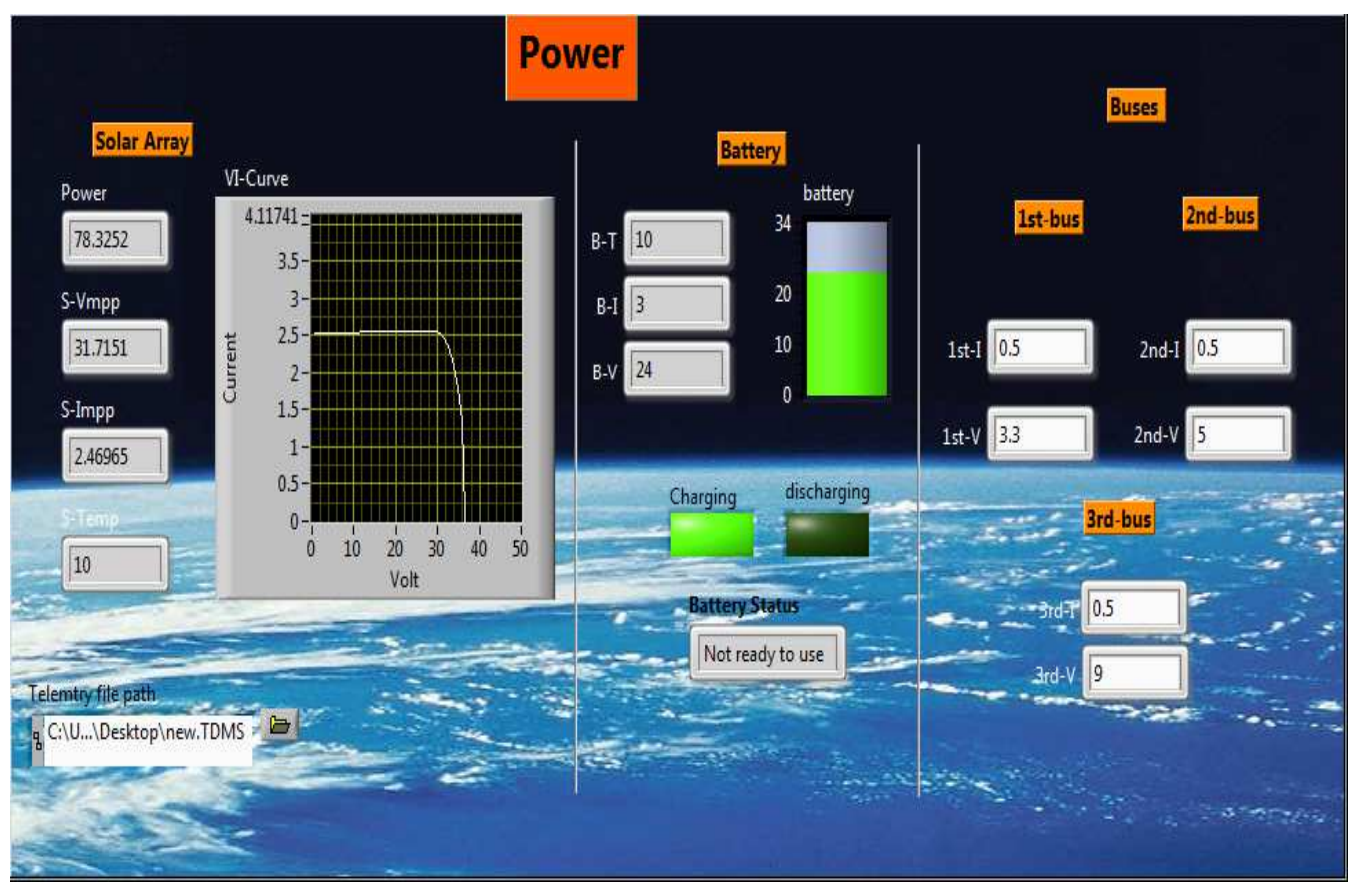

Fig. 6. Power subsystem GUI (included into satellite simulator). 


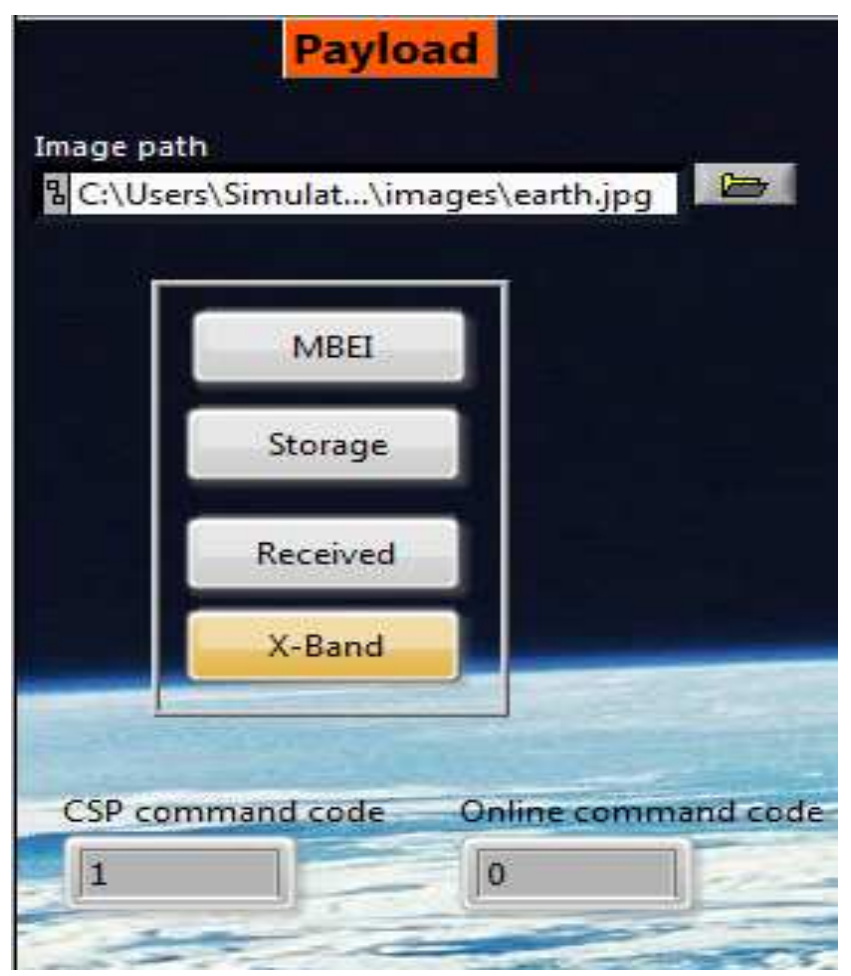

Fig. 7. Payload GUI (included into satellite simulator).

\section{Conclusion}

In this paper a new trend that using LabView program running on NI machine is used to implement satellite test center prototype with less hardware, development time, manpower and cost. From the results it is found that the new trend capable of replacing the existed STC. As a prototype, one subsystem is completely implemented (ITM) and the other test center subsystems are simulated with some of its functions and from the session that done and the results, it is found that the proposed STC is work properly.

\section{References}

[1] M.S. El-Negamy, M.B. Eteiba 1 and G.M. El-Bayoumi, "Modeling and Simulation of Egyptsat-1 Satellite System Powered by Photovoltaic Module", Journal of American Science p. 110-116, Vol. 9, No.1, 2013.

[2] Dr. J. Abdul Jaleel, Nazar. A, Omega A R, "Simulation on Maximum Power Point Tracking of the Photovoltaic Module using LabVIEW", International Journal of Advanced Research in Electrical, Electronics and Instrumentation Engineering, Vol 1, Issue 3, p.190-199, September 2012.

[3] M. Zahran, M. Okasha and Galina A. Ivanova, "Assessment of Earth Remote Sensing Microsatellite Power Subsystem Capability during Detumbling and Nominal Modes", Journal of Power Electronics, Vol. 6, No. 1, January 2006.

[4] "Flight and Camera Electronics for a Satellite System - A NI Multisim National Lab Application", www.ni.com/whitepaper/7829/en/, access: Oct 06, 2013.

[5] F. Musso, F. Bresciani, L. Bonino, S. Cesare, "NASA uses NI LabVIEW to save time, reduce costs in automated testing of Micro shutters", military aerospace solutions Conference, pp. 60-62, 2007.

[6] "Building a Satellite Navigation Test Platform Using the NI Vector Signal Transceiver"www.sine.ni.com/cs/app/doc/p/id/cs-16256.

[7] G. Huang, A. Soghoyan, D. Akopian, P. Chen, A. Samant, "A Land Mobile Channel Modeling in LabVIEW", IEEE SMC, San Antonio, TX, pp. 4575-4580, 2009.

[8] "Galileo Receiver Testing Based on LabVIEW and NI RF Hardware", www.sine.ni.com/cs/app/doc/p/id/cs-15551.

[9] Arpine Soghoyan, Grant Huang, Jayanthi Narisetty, David Akopian, "A Comprehensive Labview-Based A-GPS Receiver and Integrated Development, Simulation and Testing Platform", www.researchgate.net/publication/258567337, jan.2011.

[10] National Instruments FPGA, www.ni.com/fpga/. 